\title{
A rare cardiopulmonary parasite of the European badger, Meles meles: first description of the larvae, ultrastructure, pathological changes and molecular identification of Angiostrongylus daskalovi Janchev \& Genov 1988
}

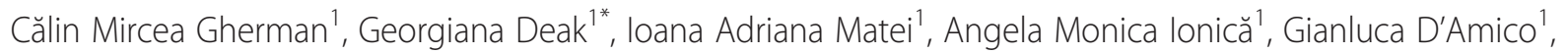
Marian Taulescu ${ }^{2}$, Lucian Barbu-Tudoran ${ }^{3}$, Alexandru Sarmaşi ${ }^{1}$, Andrei Daniel Mihalca ${ }^{1}$ and Vasile Cozma ${ }^{1}$

\begin{abstract}
Background: Angiostrongylus daskalovi is a rare cardiopulmonary nematode infecting badgers. The parasite was described in 1988 and, since then, found only once in mustelids in Europe. The present study aims to report new cases of patent $A$. daskalovi infection in badgers from northern Romania and to provide new information on its ultrastructure, molecular diagnosis, and pathology.

Methods: Eight road-killed or hunted badgers originating from Maramureș and Alba counties in Romania were collected and necropsied. Adults and larvae of cardio-pulmonary nematodes were collected and examined by light and scanning electron microscopy (SEM). Genomic DNA was extracted from adults and first-stage larvae (L1). PCR amplification of the internal transcribed spacer 2 (ITS2, 500 bp) of the rRNA gene was performed. Amplicons were purified, sequenced, and compared to those available in the GenBank database. Histopathological examination of the lungs was performed and lesions described.
\end{abstract}

Results: The necropsy revealed the presence of nematodes in the pulmonary arteries of three animals. All parasites were mature adults and the coproscopic examination showed the presence of eggs and L1 larvae in all three positive animals. Light microscopy examination confirmed the morphological and morphometric similarity of parasites to Angiostrongylus daskalovi. SEM highlighted the typical angiostrongylid structure of the rays of the copulatory bursa and the anterior extremity, with the presence of six sensory papillae surrounding the mouth opening in which a triangular tooth was visible. The first-stage larva (L1) of A. daskalovi is described here for the first time. Histopathological examination of the lungs showed chronic interstitial verminous pneumonia due to the presence of adult parasites. Molecular analysis showed $100 \%$ nucleotide similarity to an Angiostrongylus sp. isolate originating from a badger from Spain, tentatively identified as A. daskalovi.

(Continued on next page)

\footnotetext{
* Correspondence: georgiana.deak@usamvcluj.ro

'Department of Parasitology and Parasitic Diseases, Faculty of Veterinary

Medicine, University of Agricultural Sciences and Veterinary Medicine

Cluj-Napoca, Calea Mănăştur 3-5, 400372 Cluj-Napoca, Romania

Full list of author information is available at the end of the article
} 
(Continued from previous page)

Conclusions: Our study unequivocally demonstrates the presence of A. daskalovi in European badgers from Romania, provides the first description of the larvae and reveals new data about the ultrastructure of adult parasites and their pathological impact, contributing to the understanding of the phylogenetic relationships with other congeneric species.

Keywords: Angiostrongylus daskalovi, Badger, Meles meles, Romania, SEM, Histopathology, Molecular analysis

\section{Background}

The family Mustelidae is the richest group within the order Carnivora, comprising five subfamilies: Lutrinae (otters), Melinae (European badgers), Mellivorinae (honey badgers), Taxidiinae (American badgers) and Mustelinae (weasels, tayra, wolverines, martens, polecats) [1]. According to recent multigene phylogenetic analysis, the family is split into four major clades and three monotypic lineages [2]. Among all these mustelids, the European badger (Meles meles) is spread throughout Europe and in some parts of the Middle East. It is an opportunistic omnivorous species; its diet includes a broad range of animals and plants. This varied diet exposes the badger to the risk of contamination by a wide variety of cysts, eggs, larvae or intermediate hosts of certain parasites. Of these, cardiopulmonary nematodes represent a particular group, several species being reported in mustelids. The genus Aelurostrongylus Cameron, 1927 contains two species that are rarely reported in badgers in Europe: A. falciformis Schlegel, 1933 in Italy, Germany, Norway and Great Britain [3-6] and A. pridhami Anderson, 1962 in Spain. Two other metastrongyloid species belonging to the genus Angiostrongylus Kamensky, 1905 have been recorded in badgers. Angiostrongylus daskalovi Janchev \& Genov, 1988 was described from the pulmonary arteries of the European badger (M. meles) in the north-central region of Bulgaria [7] and more recently in Spain [8]. Additionally, Angiostrongylus vasorum (Baillet, 1866) was identified in the cardiopulmonary system of badgers in Switzerland, Italy and Spain [9-12]. Another species, Angiostrongylus gubernaculatus Dougherty, 1946, was described from the right ventricle of the Californian badger, Taxidea taxus neglecta in California and the California Channel Islands, the United States [13, 14].

Apart from these two genera, other lung nematodes have been reported in European badgers including Crenosoma sp., C. vulpis (Dujardin, 1845) and C. melesi Janchev \& Genov, 1988, as well as the trichuroid nematode Capillaria aerophila Creplin, 1839 [3, 4, 12, 15, 16]. Cardiopulmonary nematodes have also been reported in other mustelids like the stoat (Mustela erminea) and weasel (Mustela nivalis) infected with A. vasorum $[17,18]$ and the European pine marten (Martes martes) and the beech marten (Martes foina) infected with $A$. daskalovi [7].
The European badger is considered the typical host for A. daskalovi [7]. This nematode has a poorly known geographical distribution, so far being recorded only in Bulgaria and Spain. Moreover, the life-cycle and the host spectrum are incompletely known; the larvae are unknown and the pathological aspects have never been described. Due to these shortcomings, it is important to add new data regarding the infection caused by this nematode species. In this context, the present paper reports the first cases of patent $A$. daskalovi infection in badgers in Romania, emphasizing the ultrastructure of adult parasites and morphology of the L1 larval stage, molecular characterization, and pathological changes.

\section{Methods \\ Sample origin and collection}

Between February 2015 and April 2016, eight European badgers (Meles meles L.) were collected in the counties of Maramureș and Alba, in northern and central Romania (Fig. 1). The animals were either road-killed or hunted. Their carcasses were submitted for pathological and parasitological examination within a few hours after the death of the animals and examined immediately. During the necropsy, all nematodes found in the pulmonary arteries were collected in formalin (for morphological examination) and absolute ethanol (for molecular analysis). The classical Baermann method [19] was performed on the lung tissue and faeces, and the metastrongyloid first-stage larvae (L1) were collected. The morphology and morphometry under light microscopy of adults and larvae and SEM characteristics of adults were analysed, ten parameters being compared to other reports of angiostrongylid parasites in mustelids (Table 1).

\section{Pathology}

Full necropsy and histological examination were carried out on all badgers included in this study. Selected samples from the right atrium, pulmonary arteries, pulmonary parenchyma and tracheobronchial lymph nodes were collected for histological analysis. Samples were fixed in $10 \%$ phosphate-buffered formalin for $24 \mathrm{~h}$, routinely processed, embedded in paraffin wax, cut into $4 \mu \mathrm{m}$ sections, and stained with hematoxylin and eosin (H\&E). 


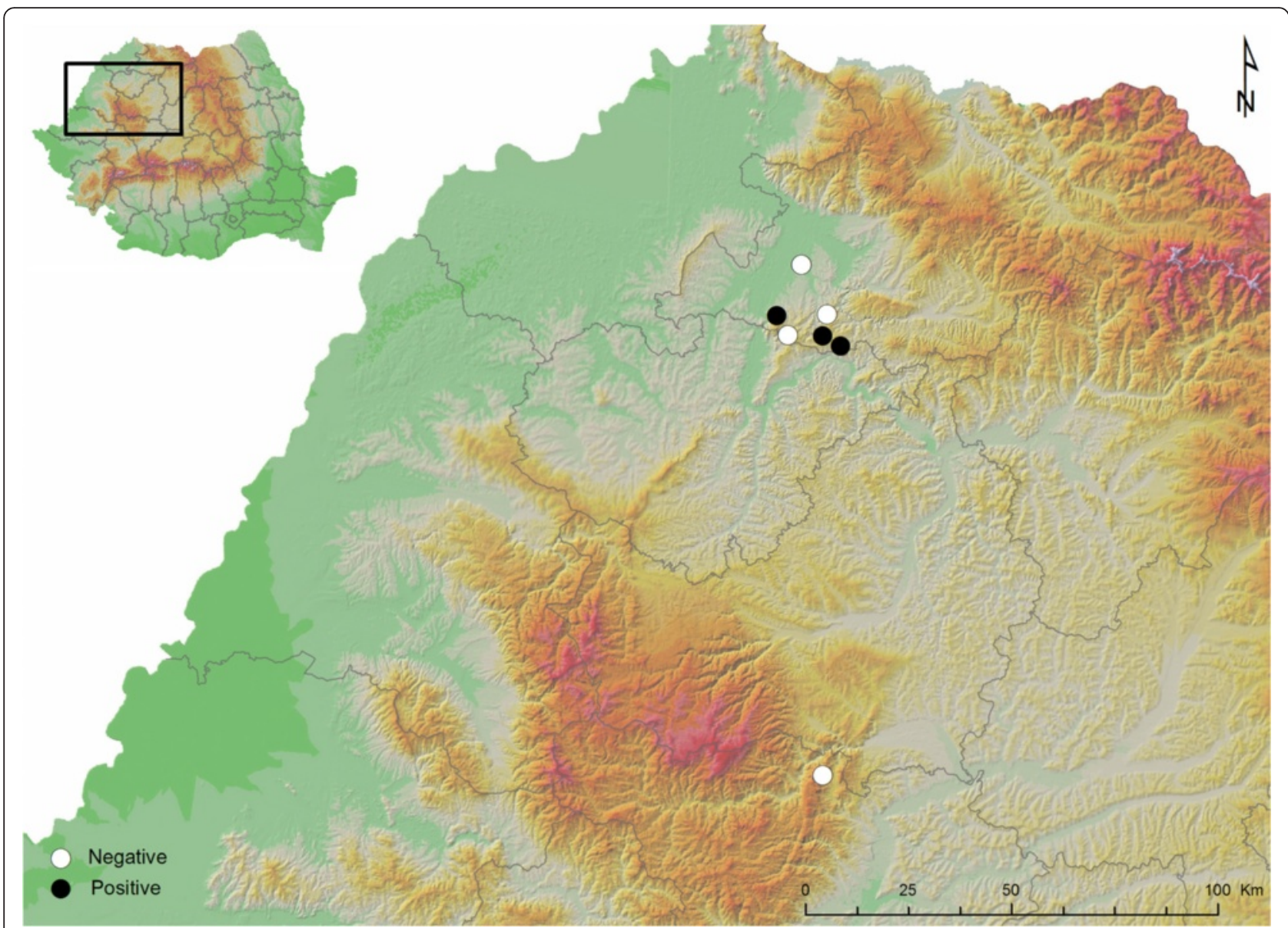

Fig. 1 Origin of the samples and positive cases

\section{Scanning electron and light microscopy}

All adult worms were washed in saline, preserved for $24 \mathrm{~h}$ in $0.5 \%$ formalin, dehydrated, cleared in lactophenol, mounted in Canada balsam and analyzed by light microscopy using an Olympus BX 61 microscope (Japan). For scanning electron microscopy, some adult parasites were fixed for $2 \mathrm{~h}$ at $4{ }^{\circ} \mathrm{C}$ in $2.7 \%$ glutaraldehyde in $0.1 \mathrm{M}$ sodium cacodylate buffer ( $\mathrm{pH}$ 7.2) and washed in PBS. Samples were post-fixed for $1 \mathrm{~h}$ with $1 \% \mathrm{OsO}_{4}$. The parasites were dehydrated in an ethanol series (30-100 \%), and infiltrated with hexamethyldisilazane, dried, mounted on aluminum stubs coated with a $10 \mathrm{~nm}$ gold layer, and examined with a Hitachi SU8230 Scanning Electron Microscope (Japan).

\section{Molecular analyses and species identification}

Genomic DNA was extracted from three adult nematodes (one from each positive animal) and $30 \mathrm{~L} 1$ stages (a pool of ten from each positive animal) using a commercial kit (Isolate II Genomic DNA Kit, Bioline, London, UK) as stated in the manufacturer's instructions. PCR amplification of the internal transcribed spacer 2 (ITS2, 500 bp) of the rRNA gene was performed using the $\mathrm{NC} 1 / \mathrm{NC} 2$ primer pair as previously described [20]. Amplicons were purified using silica membrane spin columns (QIAquick PCR Purification Kit, Qiagen, Halden, Germany) and externally sequenced by Macrogen Europe (Amsterdam). Sequences were compared to those available in the GenBank database by Basic Local Alignment Search Tool (BLAST) analysis. Phylogenetic analyses were conducted using MEGA6 software [21]. The evolutionary history was inferred by using the Maximum Likelihood method based on the Tamura-Nei model [22]. Species identification was based on morphological characteristics, associated with molecular analysis [7, 8].

\section{Results}

Morphology and morphometry of Angiostrongylus daskalovi Seven males and 16 females were collected from the pulmonary vessels of the infected badgers (Fig. 2a). Of these, 9 specimens ( 3 males and 6 females) originated from the first infected badger, two females from the 
Table 1 Morphometric features of A. daskalovi and comparative data for other Angiostrongylus spp. identified in mustelids

\begin{tabular}{|c|c|c|c|c|c|}
\hline Feature/Species & A. daskalovi & A. daskalovi & Angiostrongylus sp. (badger) & A. vasorum & A. gubernaculatus \\
\hline Source & Present study & Janchev \& Genov [7] & Gerrikagoitia et al. [8] & Costa et al. [23] & Dougherty [13] \\
\hline Male & $(n=7)$ & & & & \\
\hline Body length (mm) & $15.8-20.5$ & $13.4-21.3$ & $19.4 \pm 7.7$ & 12.4 & $18.0-19.5$ \\
\hline Body width $(\mu m)$ & $253-331$ & $254-306$ & $243 \pm 20$ & 243 & 300 \\
\hline $\begin{array}{l}\text { Distance from excretory pore to } \\
\text { cephalic end }(\mu \mathrm{m})\end{array}$ & $227-526$ & $386-463$ & $409 \pm 25$ & 373 & \\
\hline Oesophagus length $(\mu \mathrm{m})$ & $312-335$ & $336-366$ & $333 \pm 18$ & $220-275$ & $300-355$ \\
\hline Spicule length $(\mu \mathrm{m})$ & $322-352$ & $336-409$ & $346 \pm 24$ & $410-485$ & $510-560$ \\
\hline longer & $337-380$ & & & & \\
\hline Female & $(n=16)$ & & & & \\
\hline Body length (mm) & $24.0-34.0$ & $14.4-31.1$ & $25.0 \pm 14.0$ & 15.6 & $22.0-24.0$ \\
\hline Body width ( $\mu \mathrm{m})$ & $366-852$ & $340-511$ & $345 \pm 18$ & 268 & 350 \\
\hline $\begin{array}{l}\text { Distance from excretory pore to } \\
\text { cephalic end }(\mu \mathrm{m})\end{array}$ & $454-618$ & $379-636$ & $447 \pm 102$ & 403 & \\
\hline Oesophagus length $(\mu \mathrm{m})$ & $305-456$ & $356-556$ & $368 \pm 17$ & $240-280$ & $335-350$ \\
\hline Distance from vulva to anus ( $\mu \mathrm{m})$ & $203-515$ & & $295 \pm 46$ & 141 & \\
\hline Distance from vulva to caudal end $(\mu \mathrm{m})$ & $286-612$ & $269-412$ & $366 \pm 44$ & 205 & $205-250$ \\
\hline Distance from anus to caudal end $(\mu \mathrm{m})$ & 60-193 & $76-115$ & $79 \pm 3$ & 67 & $75-90$ \\
\hline Vulvar opening (length/width, $\mu \mathrm{m}$ ) & $38-40 / 4-5$ & & & & \\
\hline Anus (length/width, $\mu \mathrm{m}$ ) & $8-10 / 2-3$ & & & & \\
\hline
\end{tabular}

second and 12 (4 males and 8 females) were collected from the third animal. Adult worms exhibited a pronounced sexual dimorphism, females being larger than males, see Table 1 for detailed morphometric data for the adult worms.

Both sexes have elongated, cylindrical and slender bodies, slightly tapered at both, anterior and posterior ends (Fig. 2b). The cuticle at the anterior extremity is smooth, more or less dilated, appearing as a small cephalic vesicle (Fig. 3a). Mouth opening, in both sexes, is terminally placed, slightly triangular, being surrounded by six labial papillae each of them having a small protuberance at the top. At the level of the amphids, there are four cephalic papillae. A single rudimentary triangular tooth is visible in the buccal cavity and a small cutting plate in opposite position. Two amphidial pores are present at the anterior extremity (Fig. 3b). The buccal cavity leads into an oesophagus composed of a cylindrical corpus, slightly widened at its posterior part where it forms a bulb (Fig. 3a).

The females have a "barber pole" appearance due to their discolored uterus coiled with the brownish intestinal tract (Fig. 4a), and a slightly curved posterior extremity (Fig. 4b) showing the vulvar and anal openings on the lower curvature (Fig. 4c). The vulvar opening appears as a transverse slit (Fig. 4c). The anus is oval, transversely elongated and smaller than the vulva.

The males had a uniformly coloured body, a small bilobated copulatory bursa, and two unequal spicules. The copulatory bursa had two symmetrical, transparent,

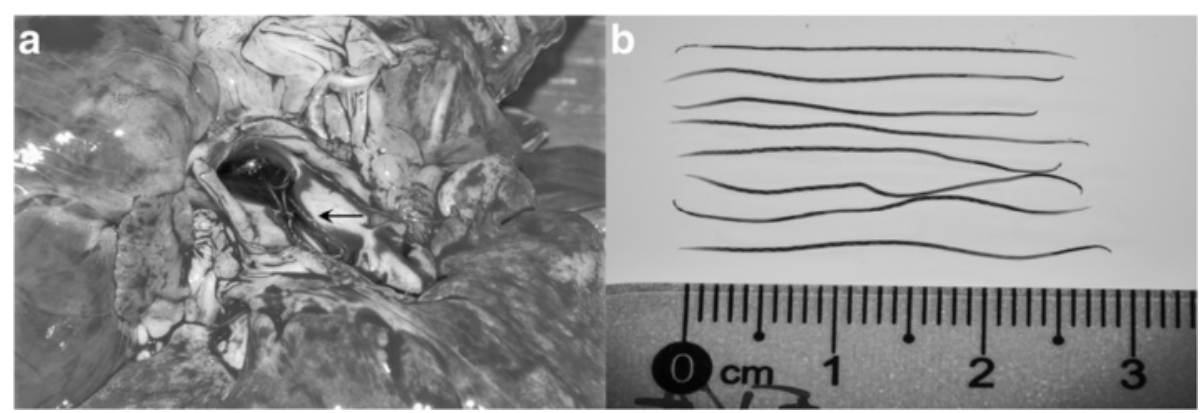

Fig. 2 a Location of Angiostrongylus daskalovi in the pulmonary arteries (arrow). b Size of A. daskalovi females 


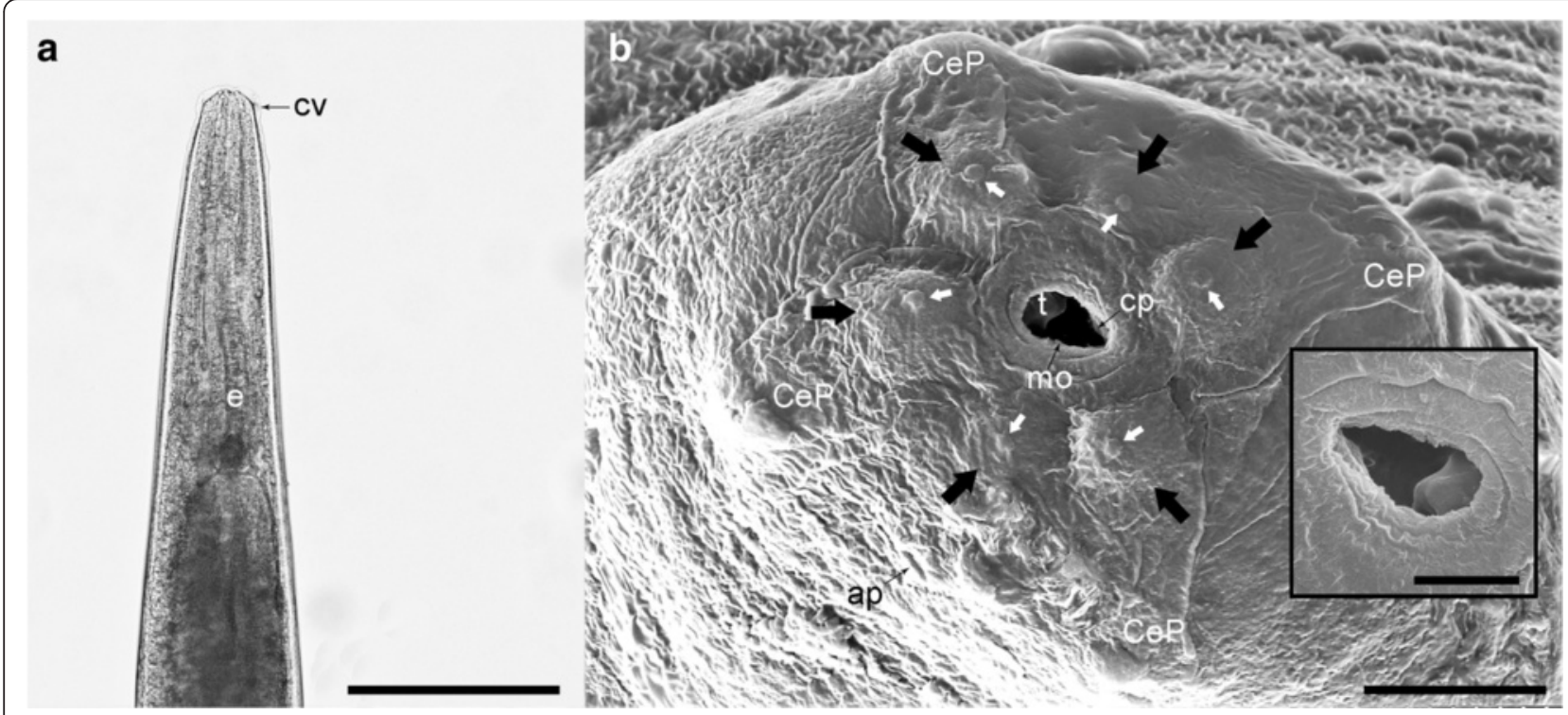

Fig. 3 Light microscopy (a) and SEM photomicrographs (b) of the anterior extremity of A. daskalovi: The tooth and the cutting plate are clearly visible in the inset. Six labial papillae (black arrows) and six small protuberances (white arrows) are indicated. Abbreviations: ap, amphidial pore; $\mathrm{CeP}$, four cephalic papillae; cp, cutting plate; cv, small cephalic vesicle; e, oesophagus; mo, mouth opening; t, tooth. Scale-bars: a, 500 $\mu$ m; b, $10 \mu \mathrm{m}$; inset $5 \mu \mathrm{m}$

ventro-lateral lobes (Fig. 5), the latter supported by rays with a variable layout and different origin: ventral, lateral, externo-dorsal and median lateral. The ventral ray is distally divided into two branches, ventro-ventral and ventro-lateral, the former being slightly shorter than the latter; ventro-lateral branch ends with a protuberance at the top. The lateral ray is split into three branches: externo-lateral, showing a protuberance at the top, medio-lateral and posterio-lateral, the last two being thinner and separated towards the terminal end. The externo-dorsal ray is straight, undivided, and smaller than the previous two. The median dorsal ray is short, thick, strong and rectangular and has two digitations. The spicules are slender, thin, brownish and unequal, with striated alae. They protrude through the cloacal opening, two papillae (papillae 7) being present behind this orifice; several papillary structures, with a presumptive sensorial role, surround the cloacal opening (Fig. 6a). The spicules show transverse striations and the distal ends are corrugated. When the spicules are joined, they form a channel probably used for semen disposal during fertilization (Fig. 6b).

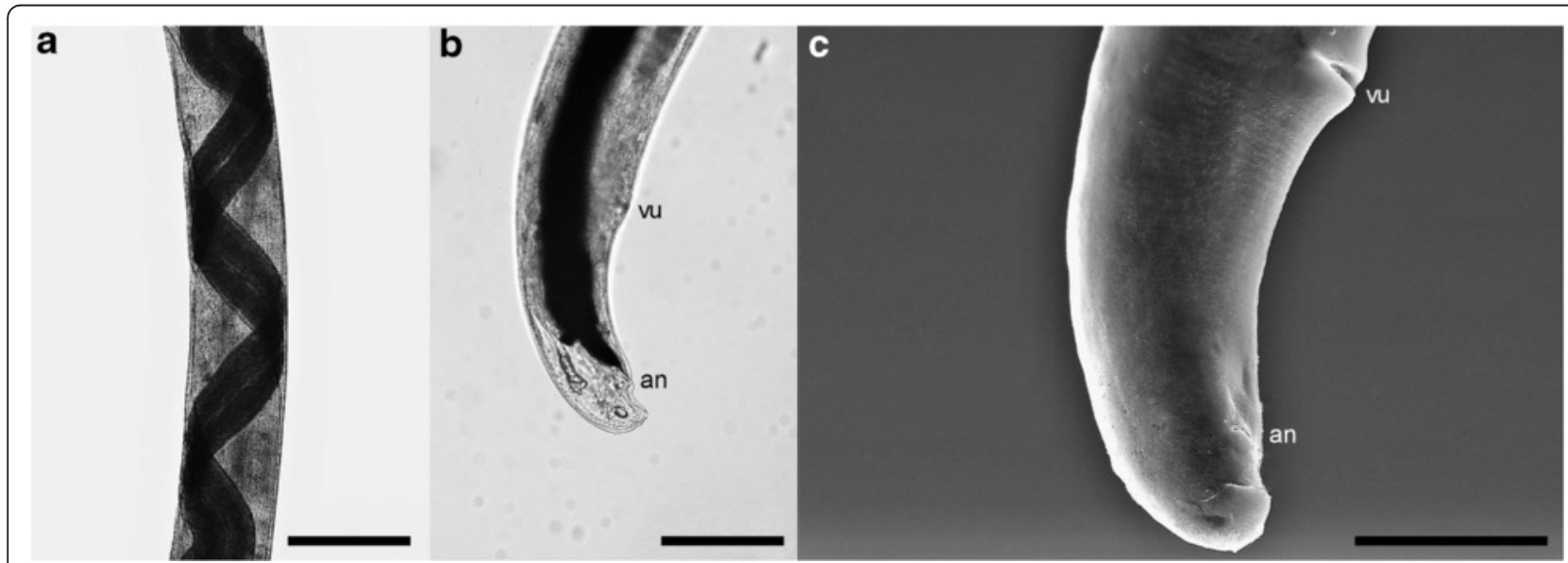

Fig. 4 Light microscopy (a, b) and SEM photomicrographs (c) of A. daskalovi female. a "Barber-pole" appearance of the body. b Slightly curved posterior extremity. c Ventral view of the posterior extremity showing the vulva (vu) and the anus (an). Scale-bars: a, $500 \mu \mathrm{m}$; b, $500 \mu \mathrm{m} ; \mathrm{c}, 100 \mu \mathrm{m}$ 

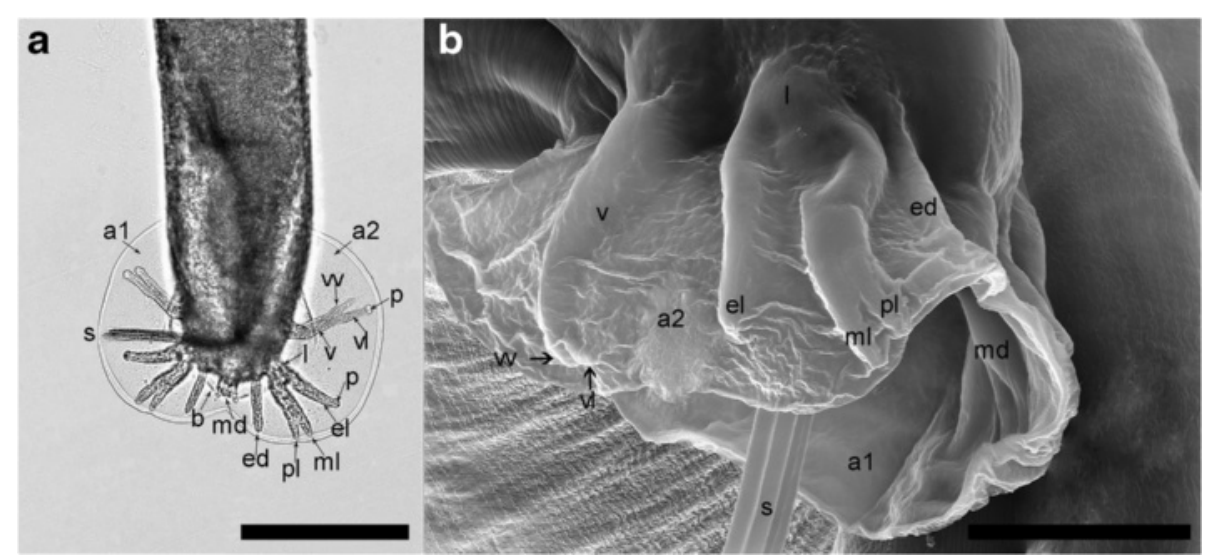

Fig. 5 Light microscopy (a) and SEM photomicrographs (b) of copulatory bursa of A. daskalovi: left ventro-lateral lobe (a1); right ventro-lateral lobe (a2); dorsal lobe (b); ventral ray (v); ventro-ventral branch of ventral ray ( $\mathrm{vv}$ ); ventro-lateral branch of ventral ray (vl); protuberances (p); lateral ray (I); externo-lateral part of lateral ray (el); medio-lateral branch of lateral ray (ml); postero-lateral branch of lateral ray (pl); externo-dorsal ray (ed); median dorsal ray (md); spicules (s). Scale-bars: a, $200 \mu \mathrm{m} ; \mathrm{b}, 50 \mu \mathrm{m}$

The measurements of eggs (mean $101 \times 79 \mu \mathrm{m}$ ) and larvae (mean $379 \times 17 \mu \mathrm{m}$ ) isolated from the lung tissue and faeces are given in Table 2. Stage-two larvae possess the typical metastrongyloid posterior end with a wavy tail, one dorsal spine, and a subterminal notch (Fig. 7a).

Microscopic examination of the Baermann sediment also revealed the presence of some eggs of $A$. daskalovi. These were embryonated, oval, with thin shells (Table 2, Fig. 7b).

\section{Pathology}

At necropsy, numerous adult worms were present in the pulmonary arteries and the right atrium, without visible gross morphological changes. The lungs showed diffuse congestion and contained several, variably-sized, firm, gray-red and slightly raised nodules that were randomly distributed within all lung lobes. The tracheobronchial lymph nodes were markedly and diffusely enlarged up to 2-3 times the normal size, irregular in shape, and gray to red on the cross section. The histological findings were consistent with chronic interstitial verminous pneumonia. The fibrous tissue and granulomatous reaction consisting of reactive macrophages, multinucleated giant cells, and fewer neutrophils, eosinophils and plasma cells, occasionally surround the larvae (Fig. 8a).

Larvae were composed of numerous round, basophilic nuclei with scant eosinophilic cytoplasm and a thin amphophilic cuticle (Fig. 8b). Scattered hemorrhagic areas associated with hemosiderin deposits, hemosiderin-laden macrophages (Fig. 8b), and coagulative necrosis were found in the affected parenchyma.

Less affected areas of the lung presented mild congestion, edema, pulmonary atelectasis and alveolar emphysema. The pulmonary arteries exhibited moderate smooth muscle hypertrophy and hyperplasia of the arterial tunica media with mild vacuolar degeneration of the endothelial cells and intimal fibrosis. Multifocal and mild subendocardial fibrosis and minimal mononuclear infiltrates were observed in the right atrium.

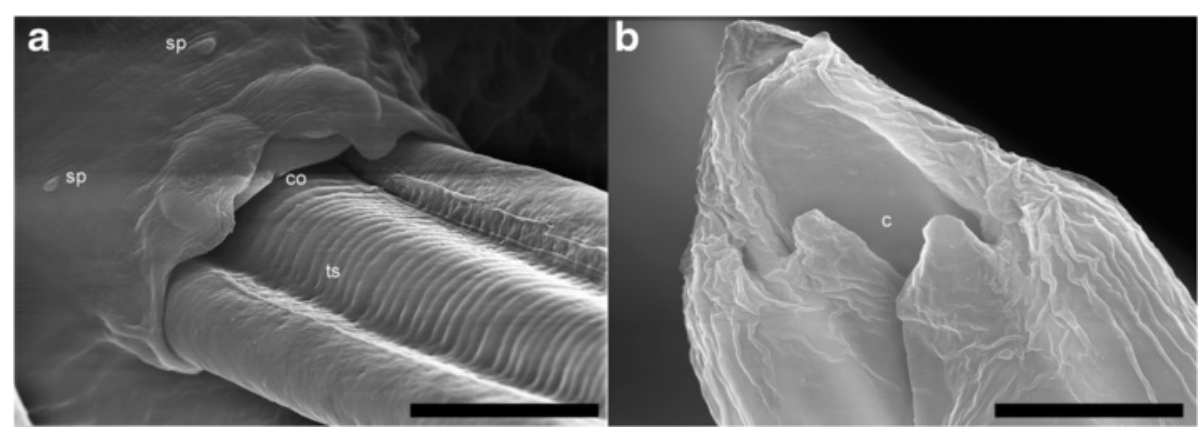

Fig. 6 SEM micrograph of adult male of A. daskalovi. a Details of the cloacal opening (co) with two papillae (papillae 7) (p), sensory papillae (sp) and transverse striations (ts) of the spicules. b Detail of the adjoining arrangement of spicules forming a channel (c). Scale-bars: a, $10 \mu \mathrm{m} ; \mathrm{b}, 5 \mu \mathrm{m}$ 
Table 2 Morphometric data for the eggs and first-stage larvae (L1) of A. daskalovi

\begin{tabular}{lllll}
\hline Species & Stage & \multicolumn{2}{l}{ Range $(\mu \mathrm{m})$} & Reference \\
\cline { 3 - 4 } & & Length & Width & \\
\hline A. daskalovi & Eggs $(n=10)^{\mathrm{a}}$ & $98-105$ & $74-90$ & Present study \\
& $\mathrm{L} 1(n=150)$ & $336-412$ & $14-20$ & Present study \\
A. chabaudi & $\mathrm{L} 1$ & $307-420$ & $15-17$ & {$[25]$} \\
& $\mathrm{L1}$ & $362-400$ & $15-18$ & {$[31]$} \\
A. vasorum & $\mathrm{L1}$ & $310-399$ & $14-16$ & {$[24,32]$} \\
\hline
\end{tabular}

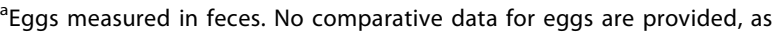
the existing data in the literature for $A$. chabaudi and A. vasorum refer to measurements of eggs in utero

The tracheobronchial lymph nodes showed diffuse reactive hyperplasia, multifocal granulomatous reaction centered on parasitic organisms and numerous aggregates of hemosiderin-laden macrophages (Fig. 8c, d). There were no microscopic lesions in the area of pulmonary arteries where adult parasites were located.

\section{Molecular analysis}

All sequences $(n=6)$ obtained from adults and larvae (GenBank accession number KX242346) were identical and showed a $100 \%$ homology to an Angiostrongylus sp. recovered from a badger from Spain (accession number GU323341). Phylogenetic analysis clustered A. daskalovi within the clade including all other European species Angiostrongylus with sequences available in the GenBank database (Fig. 9).

\section{Discussion}

This report represents the first comprehensive study of A. daskalovi infection in European badgers. The study identified this species based on morphological, morphometric and molecular analyses. Three species of Angiostrongylus are described in different badger species across the world, namely $A$. vasorum, $A$. daskalovi and $A$. gubernaculatus. Morphometrically, A. vasorum is the smallest species, the length of females ranging between $14.17-17.69 \mathrm{~mm}$ and that of males between 11.21$13.91 \mathrm{~mm}$ [23]. These values overlap the lower limits of the ranges for length of $A$. daskalovi: $14.39-31.12 \mathrm{~mm}$ in females and 13.36-21.31 $\mathrm{mm}$ in males [7]. Our data correspond to specific dimensions of $A$. daskalovi, and may differentiate these two species even if the recorded variations could be related to the intervals after infection [24]. The third species, A. gubernaculatus is morphometrically very similar to $A$. daskalovi, but host specificity and geographical range differ amongst the two species. Additionally, another congeneric species, A. chabaudi was recently found and redescribed in wildcats in the same geographical area from Romania, providing a detailed comparison of the morphometric features [25].

Scanning electron microscopy revealed similar structures of the anterior and posterior ends as described in adult $A$. vasorum [23], but also identified particular structures. At the anterior extremity, the mouth opening is surrounded by six papillae and two amphidal pores, but the small tooth observed in the mouth cavity of A. daskalovi is not known in A. vasorum. Comparison of the copulatory bursa of $A$. vasorum with that of $A$. daskalovi reveals only a slight difference in the median dorsal ray whose digitations are sometimes separated by a papilla, but none of the males of $A$. daskalovi exhibited this structure.

Despite the morphometric differences, these three species may have a common origin. Angiocaulus gubernaculatus which resembles Angiostrongylus sp., currently accepted as a synonym [26], may represent a common ancestor for the Brazilian and European populations of $A$. vasorum. Some authors consider that $A$. vasorum is the ancestral species that subsequently spread globally with its carnivore hosts, and evolved into genetically distinct populations in various host species [27]. The phylogenetic analysis performed herein is also supportive of this hypothesis, as $A$. daskalovi clustered with $A$. vasorum.

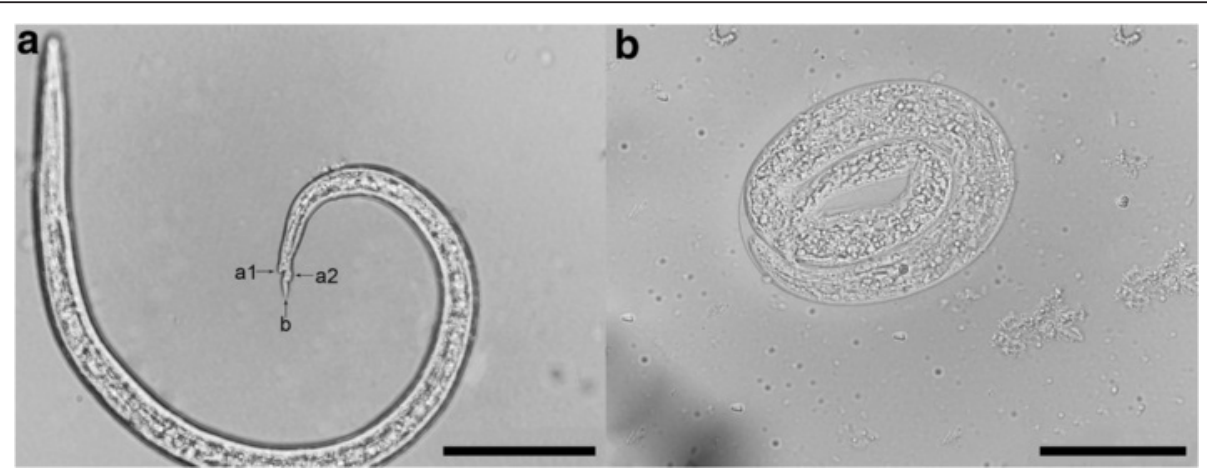

Fig. 7 Light microscopy photomicrographs of A. daskalovi. L1 larva. a Posterior extremity of L1 larva: dorsal spine (a1); subterminal notch (a2); wavy tail (b). b Egg. Scale-bars: a, $50 \mu \mathrm{m} ; \mathrm{b}, 50 \mu \mathrm{m}$ 


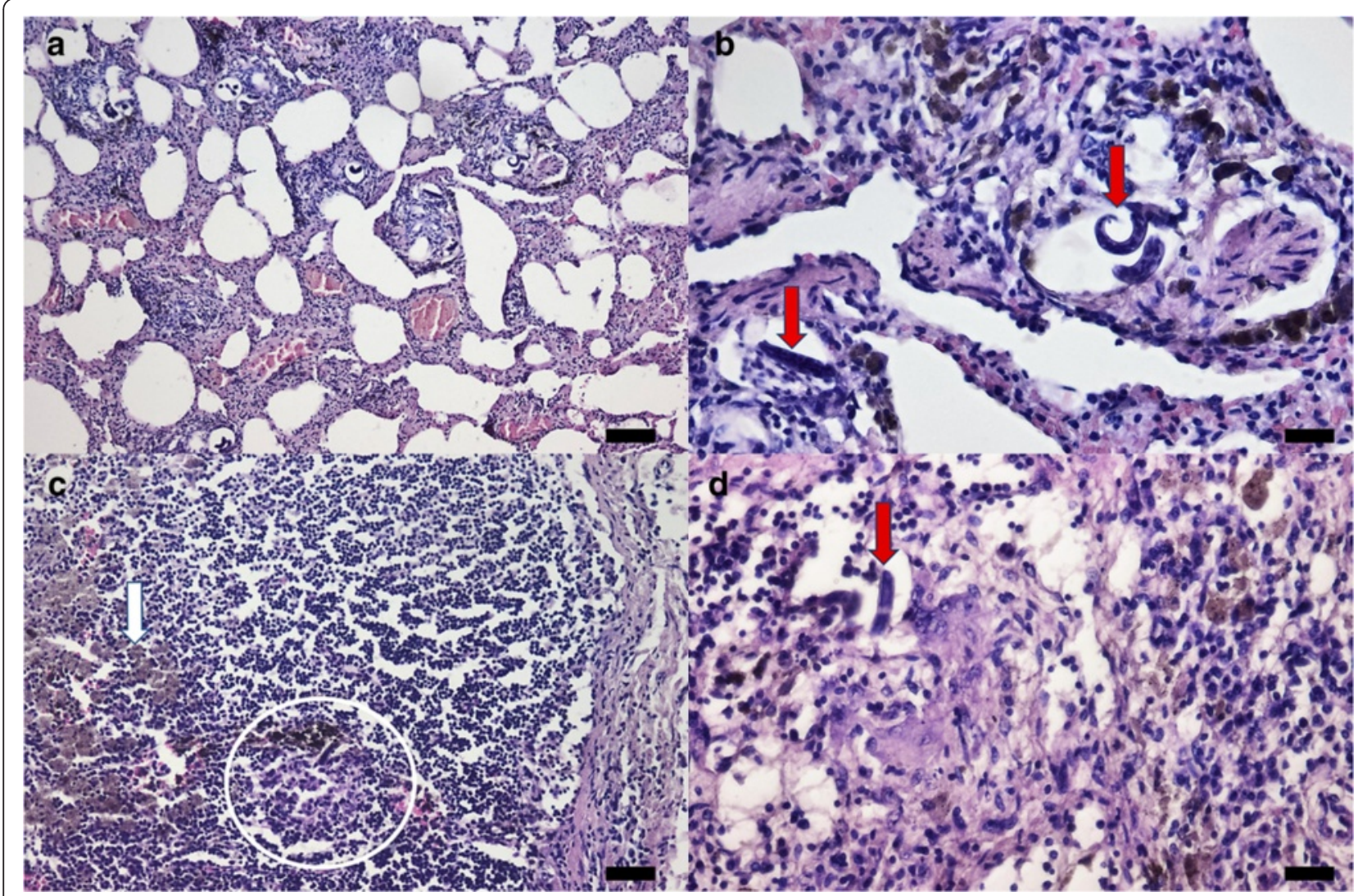

Fig. 8 Histological sections (haematoxylin-eosin staining) of the lung and tracheobronchial lymph nodes of badgers infected with A. daskalovi. a Diffuse hyperemia, fibrosis and granulomatous reaction of the pulmonary interstitium. $\mathbf{b}$ Coiled larvae in the bronchial tree and interstitium (red arrows). c Hemosiderin deposits (white arrow) and granulomatous reaction surrounding fragments of parasites (white circle) in the tracheobronchial lymph node. $\mathbf{d}$ Detail of granulomatous reaction centered on larvae (red arrow) in the tracheobronchial lymph node. Scale-bars: a, $100 \mu \mathrm{m}$; b, $20 \mu \mathrm{m} ; \mathrm{c}, 50 \mu \mathrm{m} ; \mathrm{d}, 20 \mu \mathrm{m}$

To our knowledge, this is the first description of the first-stage larva (L1) of $A$. daskalovi. The differentiation of first-stage larvae of different Angiostrongylus species is difficult due to several common characters such as the transparent body, sigmoid tail, the presence of a dorsal spine and a visible notch. Their lengths partly overlap from one species to another: $310-400 \mu \mathrm{m}$ for $A$. vasorum and $336-412 \mu \mathrm{m}$ for $A$. daskalovi in the present study (L1s of A. gubernaculatus are not described). This does not allow a clear differentiation based on morphological and morphometric criteria. However, the adults and larvae of $A$. daskalovi identified in this study were $100 \%$ similar to adults of Angiostrongylus sp. recovered from a badger in Spain and tentatively identified, based on morphology and morphometry, as A. daskalovi [8].

The presence of molting larvae in tracheobronchial lymph nodes and eggs in the lung parenchyma provides evidence that the life-cycle of $A$. daskalovi is probably similar to that of $A$. vasorum, following the type II of the known development in the definitive hosts [28]. During their migration, larvae may exert a significant pathogenic action. Hypertrophy and hyperplasia of the arterial tunica media are explainable by pulmonary hypertension due to the presence of nematodes in the lung arteries, being similar to those lesions recorded in dogs naturally infected with $A$. vasorum [29]. The presence of hemosiderin deposits and hemosiderin-laden macrophages, edema, pulmonary atelectasis, alveolar emphysema, diffuse congestion of the lungs and the presence of the nodules randomly distributed within all lung lobes are similar to those produced by A. vasorum in dogs [30]. All these pathological alterations of the lungs and the pulmonary arteries confirm that $A$. daskalovi might play an important pathogenic role in infected badgers.

Although the species of Angiostrongylus infecting carnivores seem to show a relatively well-defined host specificity, some studies report certain overlaps. As badgers can occasionally be infected with $A$. vasorum, dogs might also be infected occasionally with $A$. daskalovi. Our new molecular data and larval morphology can partly solve possible misdiagnosis problems in European carnivores. Still to be solved is the life-cycle of $A$. daskalovi. 


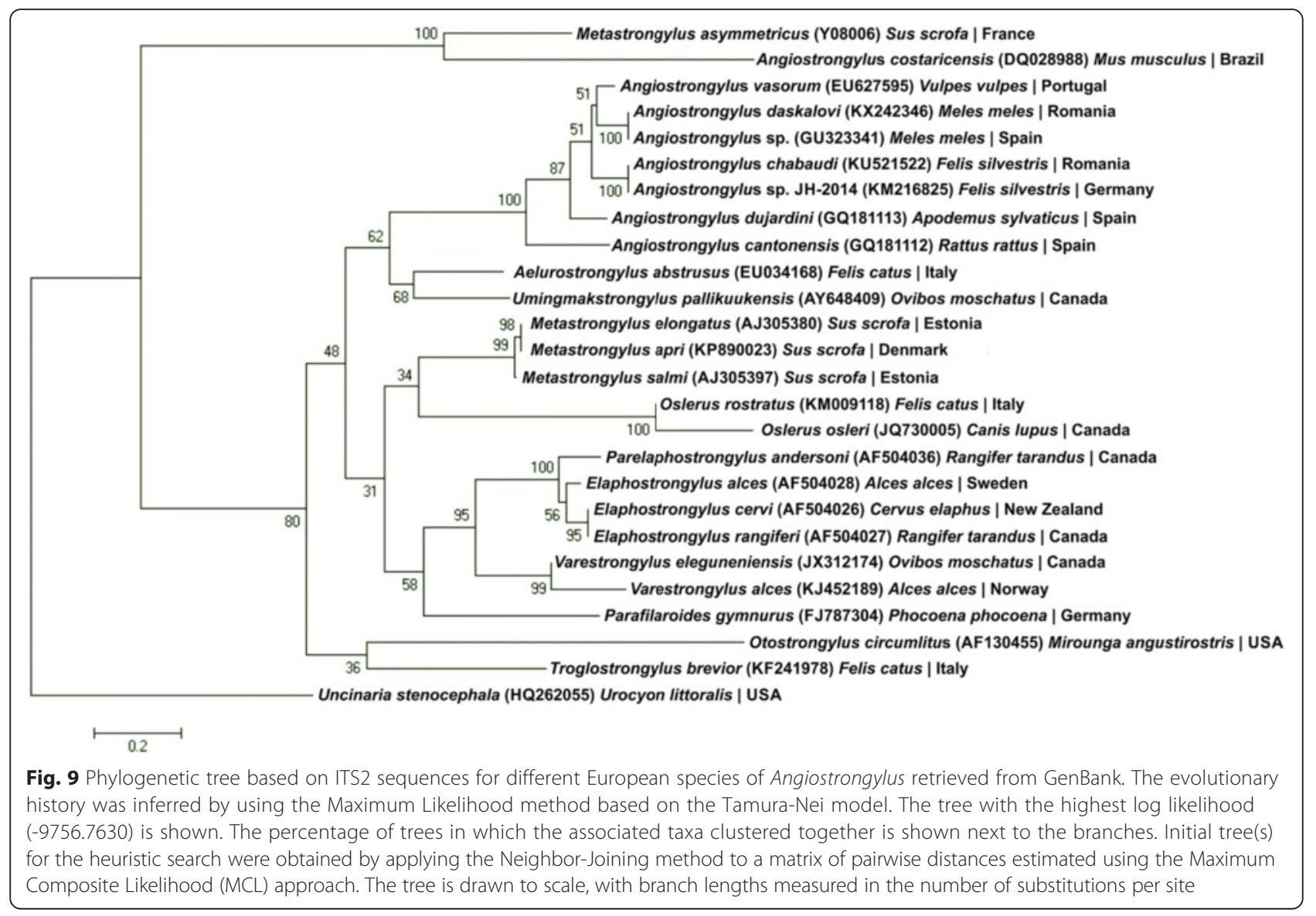

\section{Conclusions}

The current study confirms the existence of $A$. daskalovi patent infection in badgers from Romania and provides the first description of the larvae, its pathological effect, and its phylogenetic relationships with other congeneric species.

\section{Abbreviations}

BLAST, Basic local alignment search tool analysis; DNA, deoxyribonucleic acid; H\&E, Hematoxylin and eosin; L1, First larval stage; PCR, polymerase chain reaction; SEM, Scanning electron microscopy

\section{Acknowledgments}

We are indebted to Cristian Domșa for preparing the map and to all the people and hunters which provided the dead badgers.

\section{Funding}

This study was supported by UEFISCDI Grant PCE 236/2011.

Availability of data and materials

The data supporting the conclusions of this article are included within the article.

\section{Authors' contributions}

$C M G, A D M$ and $V C$ conceived and designed the study. GD and GD'A performed the necropsy. IAM and AMI performed molecular analysis of the parasites. MT conducted the histopathological study. LBT conducted the SEM analysis. AS collected the carcasses of the badgers. CMG wrote the paper. All authors contributed to improve the manuscript and read and approved the final version.
Competing interests

The authors declare that they have no competing interests.

Consent for publication

Not applicable.

Ethics approval and consent to participate

Not applicable.

\section{Author details}

${ }^{1}$ Department of Parasitology and Parasitic Diseases, Faculty of Veterinary Medicine, University of Agricultural Sciences and Veterinary Medicine

Cluj-Napoca, Calea Mănăştur 3-5, 400372 Cluj-Napoca, Romania. ${ }^{2}$ Department of Pathology, Faculty of Veterinary Medicine, University of Agricultural

Sciences and Veterinary Medicine Cluj-Napoca, Calea Mănăştur 3-5, 400372 Cluj-Napoca, Romania. ${ }^{3}$ Department of Molecular Biology and Biotechnology, Faculty of Biology and Geology, Babes-Bolyai University, M. Kogălniceanu Street, 1, Cluj-Napoca 400648, Romania.

Received: 14 June 2016 Accepted: 22 July 2016

Published online: 02 August 2016

References

1. Simpson GG. The principles of classification and a classification of mammals. Bull Am Mus Nat Hist Bulletin. 1945;85:1-350.

2. Koepfli KP, Deere KA, Slater GJ, Begg C, Begg K, Grassman L, et al. Multigene phylogeny of the Mustelidae: resolving relationships, tempo and biogeographic history of a mammalian adaptive radiation. BMC Biol. 2008;6:10.

3. Magi M, Banchi C, Barchetti A, Guberti V. The parasites of the badger (Meles meles) in the north of Mugello (Florence, Italy). Parassitologia. 1999;41:533-6.

4. Stubbe M. Zur Biologie der Raubtiere eines abgeschlossenen Waldgebietes. Z Jagdwiss. 1965;11:73-102. 
5. Davidson RK, Handeland K, Gjerde B. The first report of Aelurostrongylus falciformis in Norwegian badgers (Meles meles). Acta Vet Scand. 2006;48:6.

6. Jones GW, Neal C, Harris EA. The helminth parasites of the badger (Meles meles) in Cornwall. Mammal Rev. 1980;10:163-4.

7. Janchev J, Genov T. Angiostrongylus daskalovi spp. (Nematoda: Filaroididae) from Mustelidae in Bulgaria. Helminthologia (Bratislava). 1988:252:81-8.

8. Gerrikagoitia X, Barral M, Juste RA. Angiostrongylus species in wild carnivores in the Iberian Peninsula. Vet Parasitol. 2010;174(1-2):175-80.

9. Miquel J, Feliu C, Torres J, Casanova JC. Corología de las especies de nematodos parásitas de carnívoros silvestres en Cataluña (NE península ibérica). Misc Zool. 1993;17:49-57.

10. Origgi FC, Plattet P, Sattler U, Robert N, Casaubon J, Mavrot F, et al. Emergence of canine distemper virus strains with modified molecular signature and enhanced neuronal tropism leading to high mortality in wild carnivores. Vet Pathol. 2012;49(6):913-29.

11. Magi M, Guardone L, Dell'omodarme M, Prati MC, Mignone W, Torracca B, et al. Angiostrongylus vasorum in red foxes (Vulpes vulpes) and badgers (Meles meles) from central and northern Italy. Hystrix It J Mamm. 2009;20(2):121-6.

12. Torres J, Miquel J, Motjé M. Helminth parasites of the Eurasian badger (Meles meles L.) in Spain: a biogeographic approach. Parasitol Res. 2001; 87(4):259-63.

13. Dougherty EC. The genus Aelurostrongylus Cameron, 1927 (Nematoda: Metastrongylidae), and its relatives; with descriptions of Parafilaroides, gen. nov., and Angiostrongylus gubernaculatus, sp. nov. Proc Helminthol Soc Wash. 1946;13:16-26.

14. Faulkner CT, Patton S, Munson L, Johnsont EM, Coonan TJ. Angiocaulus gubernaculatus in the island fox (Urocyon littoralis) from the California Channel Islands and comments on the diagnosis of angiostrongylidae nematodes in canid and mustelid hosts. J Parasitol. 2001;87(5):1174-6.

15. Millán J, Sevilla I, Gerrikagoitia X, García-Pérez AL, Barral M. Helminth parasites of the Eurasian badger (Meles meles L.) in the Basque Country (Spain). Eur J Wildl Res. 2004;50:37-40.

16. Popiołek $M$, Jarnecki $H$, Łuczyński $T$. A record of Crenosoma vulpis (Rudolphi, 1819) (Nematoda, Crenosomatidae) from the Eurasian badger (Meles meles L.) from Poland. Wiad Parazytol. 2009:55(4):437-9.

17. Simpson V. Angiostrongylus vasorum infection in a stoat. Vet Rec. 2010; 166(6):182.

18. Simpson VR, Tomlinson AJ, Stevenson K, McLuckie JA, Benavides J, Dagleish MP. A post-mortem study of respiratory disease in small mustelids in south-west England. BMC Vet Res. 2016;12(1):72.

19. Willcox HP, Coura JR. A new design of the Baermann, Moraes, Coutinho's technique for the isolation of nematode larva (Article in Portuguese). Mem Inst Oswaldo Cruz. 1989;84(4):563-5.

20. Gasser RB, Chilton NB, Hoste H, Beveridge I. Rapid sequencing of rDNA from single worms and eggs of parasitic helminths. Nucleic Acids Res. 1993;21(10):2525-6

21. Tamura K, Stecher G, Peterson D, Filipski A, Kumar S. MEGA6: Molecular Evolutionary Genetics Analysis version 6.0. Mol Biol Evol. 2013;30(12):2725-9.

22. Tamura K, Nei M. Estimation of the number of nucleotide substitutions in the control region of mitochondrial-DNA in humans and chimpanzees. Mol Biol Evol. 1993;10(3):512-26.

23. Costa JO, De Araúijo Costa HM, Guimarães MP. Redescription of Angiostrongylus vasorum (Baillet, 1866) and systematic revision of species assigned to the genera Angiostrongylus Kamensky, 1905 and Angiocaulus Schulz. 1951. Rev Méd Vét. 2003;154:9-16.

24. Rosen L, Ash LR, Wallace GD. Life history of the canine lungworm Angiostrongylus vasorum (Baillet). Am J Vet Res. 1970;31:131-43.

25. Gherman CM, lonică AM, D'Amico G, Otranto D, Mihalca AD. Angiostrongylus chabaudi (Biocca, 1957) in wildcat (Felis silvestris silvestris) from Romania. Parasitol Res. 2016;115(6):2511-7.

26. Anderson $\mathrm{ClH}$. Keys to genera of the superfamily Metastrongyloidea. In: Anderson RC, editor. Keys to the nematode parasites of vertebrates No. 5. Farnham Royal, Bucks.: Commonwealth Agricultural Bureau; 1978. p. 1-40.

27. Morgan ER, Clare EL, Jefferies R, Stevens JR. Parasite epidemiology in a changing world: can molecular phylogeography help us tell the wood from the trees? Parasitology. 2012;139(14):1924-38.

28. Spratt DM. Species of Angiostrongylus (Nematoda: Metastrongyloidea) in wildlife: A review. Int J Parasitol Parasites Wildl. 2015;4(2):178-89.

29. Borgeat K, Sudunagunta S, Kaye B, Stern J, Luis Fuentes V, Connolly DJ. Retrospective evaluation of moderate-to-severe pulmonary hypertension in dogs naturally infected with Angiostrongylus vasorum. J Small Anim Pract. 2015;56:196-202.

30. Rinaldi L, Cortese L, Meomartino L, Pagano TB, Pepe P, Cringoli G, Papparella S. Angiostrongylus vasorum: epidemiological, clinical and histopathological insights. BMC Vet Res. 2014;10:236.

31. Diakou A, Psalla D, Migli D, Di Cesare A, Youlatos D, Marcer F, Traversa D. First evidence of the European wildcat (Felis silvestris silvestris) as definitive host of Angiostrongylus chabaudi. Parasitol Res. 2016;115(3):1235-44.

32. Bolt G, Monrad J, Koch J, Jensen AL. Canine angiostrongylosis: a review. The Veterinary Record. 1994;135(19):447.

\section{Submit your next manuscript to BioMed Central and we will help you at every step:}

- We accept pre-submission inquiries

- Our selector tool helps you to find the most relevant journal

- We provide round the clock customer support

- Convenient online submission

- Thorough peer review

- Inclusion in PubMed and all major indexing services

- Maximum visibility for your research

Submit your manuscript at www.biomedcentral.com/submit
Biomed Central 